\title{
Spatial Differentiation and Influencing Factors of Poverty Alleviation Performance Under the Background of Sustainable Development: A Case Study of Contiguous Destitute Areas in Hunan Province, China
}

\author{
TAN Xuelan, YU Hangling, AN Yue, WANG Zhenkai, JIANG Lingxiao, REN Hui \\ (College of Resources and Environment, Hunan Agricultural University, Changsha 410128, China)
}

\begin{abstract}
Poverty eradication is a realistic requirement for the addressing of the urban-rural development imbalance. It consolidates the achievements of the poverty alleviation, and accelerates the realization of the United Nations Sustainable Development Goals. In research that deals with poverty, qualitative analysis is often used to study the connection between a single influencing factor and poverty reduction, and to solve regional poverty through government measures. However, these studies usually ignore the multidimensional nature of poverty, and the fact that poverty alleviation also needs to be approached from multiple perspectives. By constructing a theoretical framework of poverty alleviation performance from the perspective of sustainable development, this study selects contiguous poverty-stricken areas in the Hunan Province, China as the empirical study area, constructs an evaluation index system from the three dimensions of economic development, infrastructure and people's livelihood security, and selects influencing factors from three aspects of 'population', 'land' and 'industry'. The spatial differentiation characteristics and influencing factors of poverty alleviation performance in poverty-stricken areas were studied by using the methods of entropy weight method and geodetector. The results show: firstly, in the concentrated and contiguous poverty-stricken areas of the Hunan Province, the performance of poverty alleviation in the economic development makes little difference, showing a 'high-medium-low' cross-distribution pattern. The poverty alleviation performance of the infrastructure presents a distribution pattern of 'low in the middle and high on both sides. The poverty alleviation performance of people' $\mathrm{s}$ livelihood security has significant spatial differentiation characteristics, which all present a reunion distribution. The overall poverty alleviation performance varies greatly, showing a funnel-shaped distribution in space. Secondly, the spatial differentiation of poverty alleviation performance in the concentrated and contiguous poverty-stricken areas of the Hunan Province is the result of the combined effects of multiple factors. 'Population' is the dominant factor affecting the performance of poverty alleviation, 'land' is the basic factor that causes the spatial differentiation of poverty alleviation performance, and 'industry' is the key factor for the improvement of the poverty alleviation ability.
\end{abstract}

Keywords: poverty alleviation performance; space differentiation; geodetector; influencing factors; Hunan Province

Citation: TAN Xuelan, YU Hangling, AN Yue, WANG Zhenkai, JIANG Lingxiao, REN Hui, 2021. Spatial Differentiation and Influencing Factors of Poverty Alleviation Performance Under the Background of Sustainable Development: A Case Study of Contiguous Destitute Areas in Hunan Province, China. Chinese Geographical Science, 31(6): 1029-1044. https://doi.org/10.1007/s11769-021-1242-4

\section{Introduction}

Poverty is a global, socio-economic problem that the en- tire world can not keep on ignoring (Wang et al., 2018). Poverty eradication is an important prerequisite for the achievement of the Sustainable Development Goals

\footnotetext{
Received date: 2021-05-21; accepted date: 2021-09-17

Foundation item: Under the auspices of the National Natural Science Foundation of China (No. 41971219, 41571168), Natural Science Foundation of Hunan Province (No. 2020JJ4372), Philosophy and Social Science Fund Project of Hunan Province (No. 18ZDB015) Corresponding author: AN Yue; E-mail: 954221276@qq.com

(C) Science Press, Northeast Institute of Geography and Agroecology, CAS and Springer-Verlag GmbH Germany, part of Springer Nature 2021
} 
(SDGs) worldwide. In accordance with the extreme poverty line (living cost less than 1.9 US $\$$ / d) proposed by the World Bank, by the end of 2019, the proportion of the global population living in extreme poverty stood at about $8.4 \%$ (https://www.worldbank.org/en/topic/ poverty). Between 88 and 115 million people around the world have fallen back below the extreme poverty line as a result of COVID-19. About 120 million more people were living in poverty in 2020 , and the total is expected to rise to about 150 million by the end of 2021 (https://www.worldbank.org/en/topic/measuringpoverty). Poverty has become the main obstacle to achieving the SDGs (Padda and Hameed, 2018). Therefore, poverty reduction has become an important task for many countries around the world (Magombeyi and Odhiambo, 2018; Callixte et al., 2020; Nhung, 2020). China used to be a developing country with the largest number of rural poverty in the world. Poverty characteristics such as deep poverty, wide scope, and complicated causes of poverty have made China's poverty problem very prominent. Poverty governance is the focus of the work of the Chinese government. Since the Reform and Opening Up, China has taken a series of steps with the goal of reducing poverty, and as a result, made remarkable achievements. It has become the first country in the United Nations (UN) to achieve the Millennium Development Goal of halving the impoverished population, and has made great contributions to the global poverty reduction and development cause (Guo and Zhou et al., 2018; Rogers et al., 2020). Hunan Province was the first place where General Secretary Xi Jinping proposed targeted poverty alleviation. After nearly $10 \mathrm{yr}$ of hard work, decisive achievements have been made in the process of poverty alleviation. By the end of 2020, all of the 51 impoverished counties in the province have been lifted out of poverty, and 6920 impoverished villages have all been listed, 682 of all of the poverty-stricken people in 10000 rural areas have been lifted out of poverty, and absolute poverty and regional overall poverty have been eliminated (http://www.hunan.gov. cn/hnszf/hnyw/sy/hnyw1/202105/t20210501_16523040. $\mathrm{html}$ ). Therefore, the evaluation of the performance of poverty alleviation in the Hunan Province, and the study of its influencing factors are of great significance for the consolidation of the effect of poverty alleviation and sustainable development in poor areas of the world.

Presently, eliminating absolute poverty has become an important topic for scholars all over the world (Dunford et al., 2020; Ponce et al., 2020; Tesema, 2020). The United Nations first defined 'extreme poverty' in 1995 as 'an extreme lack of necessities for survival, including lack of food, water, sanitation, shelter, health care, education, and information, not only due to very low income but also lack of facilities and services'. Subsequently, the research, with the focus on the concept of poverty, expanded from absolute extreme poverty to multidimensional poverty (Habtewold, 2021), and spatial poverty (Zandi et al., 2019). By studying the spatial characteristics and rules of the geographical capital, the clustering degree of spatial poverty can be judged in the form of a map. For the measurement and determination of poverty, the Human Poverty Index established by the United Nations Development Program (UNDP), the General Poverty Index (GDI) established by Townsend (Langlois and Kitchen, 2001), and the Multidimensional Poverty Index established by Alkire and Santos (Alkire and Santos, 2010) all have accurate measurement effect. In terms of poverty reduction, some scholars use the multidimensional poverty index to evaluate poverty (Bahrami and Hashimee, 2019), discuss poverty reduction (Shabbir et al., 2019), and formulate the policies concerning poverty reduction (Leventi et al., 2019). On the other hand, more scholars formulate poverty reduction policies by studying the impact of social factors on poverty (Urbano et al., 2021). For example, microfinance is analyzed in order to have a better understanding of poverty reduction. Microfinance can play an important role in reducing poverty and improving the socioeconomic situation of the poor, and users of microfinance receive benefits, which in turn promotes poverty reduction (Rajesha and Alok, 2018; Geremewe, 2019). The distribution of commercial buses is studied in order to understand whether buses can play a role in poverty reduction. It is believed that the activities of commercial buses reduce poverty in the Yobe State (Akinlolu and Maina, 2020). The establishing of agricultural cooperatives in rural areas, the development of specialized agricultural production, the increase of agricultural productivity, and the increase in employment and income in rural areas, are all used to achieve the goal of poverty eradication (Umidjanovich, 2020; Sikandar et al., 2021). Unlike international scholars, most Chinese scholars explore poverty and poverty reduction from multiple dimensions, through empirical analysis. Re- 
search on geographic identification (Liu et al., 2017), spatial differentiation (Zheng et al., 2021), and the driving mechanism of poverty (Liu et al., 2019) have gradually become a relatively complete poverty research system. The measurement and identification of poverty have expanded from a single dimension of income or consumption, to multiple dimensions which encompass the economy, education, infrastructure, public services, living environment, etc. (Li et al., 2020). In terms of spatial differentiation and classification of poverty, Chinese scholars have analyzed the differentiation characteristics of the spatial pattern of poverty and made the classification of poverty types, and the selection of regulatory paths (Tan et al., 2019) from different scales, such as national (Jin et al., 2020), regional (Zhao et al., 2020), municipal (Du et al., 2020), county (Wu et al., 2018), and village (Dou et al., 2018). In terms of the research of the poverty-driven mechanisms, quantitative analysis methods such as the geodetector model (Zhou and Li, 2019), PSR model (Hu and Zeng, 2019), and GTOPSIS model (Qi et al., 2020) are all used to identify the main factors which cause poverty. At the same time, with the implementation of China's poverty alleviation policy, the poverty alleviation performance and antipoverty model have gradually become the new direction of poverty research, with the main focus being on the evaluation of poverty alleviation (Zhu et al., 2018; Wang et al., 2020), poverty alleviation model, and the selection of poverty alleviation path (Li et al., 2018). To sum up, these studies on poverty and the modeling of the poverty index accurately reflect the spatial distribution characteristics of poor areas, and explore and analyze the influencing factors, occurrence mechanisms, anti-poverty policies, and poverty alleviation paths. However, from the perspective of sustainable development, by means of combining theoretical discussion with empirical analysis, the spatial differentiation and influencing factors of regional poverty alleviation performance are quantitatively analyzed, and the research on regional sustainable development strategy is relatively lacking.

In this study, the county-level poverty alleviation theory was constructed from the perspective of sustainable development, and then the contiguously povertystricken counties in the Hunan Province of China were taken as the study area. The evaluation index system of poverty alleviation in combination with the national poverty alleviation standard was selected. Based on the economic development, and infrastructure, the performance of people's livelihood security from the three dimensions of space pattern is analyzed. The geodetector of 'population', 'land', 'industry' is used to identify the dominant factors which influence these three aspects, grasp the actuality of the regional poverty alleviation, and consolidate the performance of anti-poverty measures, which are then put forward.

\section{Materials and Methods}

\subsection{Study area}

This study chose the Hunan Province as the research area. It is located in central China, and is surrounded by mountains on three sides (Fig. 1). Mountains and hills account for $66.62 \%$ of the total land area of the province. There are 122 county-level administrative districts under the jurisdiction of the province, 41 poverty alleviation counties in concentrated contiguous destitute areas (the Wuling Mountains and the Luoxiao Mountains), and 10 poverty alleviation counties in the non-contiguous contiguous destitute areas. In 2019, a total of 20 poverty-stricken counties in the Hunan Province have been lifted out of poverty, all 718 villages that had been listed as poor were listed, and 630000 rural impoverished people had been lifted out of poverty. So far, all 51 poor counties in the Hunan Province have been lifted out of poverty, and the poverty incidence rate has dropped to $0.36 \%$. The country's poverty alleviation goals and tasks set by the state by the end of 2020 on schedule (http://www.hunan. gov.cn/hnyw/DJ2019/jztp/sgxx2/xdg12/shengz2/202001/ t20200121_11162403.html).Therefore, taking the Hunan Province, and its influencing factors of its poverty alleviation performance, as research samples for poverty alleviation counties in the concentrated contiguous poverty-stricken areas, are strong, typical representatives for the analysis of the spatial distribution pattern.

\subsection{Data sources}

The socio-economic data utilized in this paper are mainly obtained indirectly through the Hunan Statistical Yearbook (Hunan Provincial Bureau of Statistics, 2020), Hunan Survey Yearbook (National Bureau of Statistics, 2020), Hunan Rural Statistical Yearbook (Hunan Provincial Bureau of Statistics, 2020), the offi- 


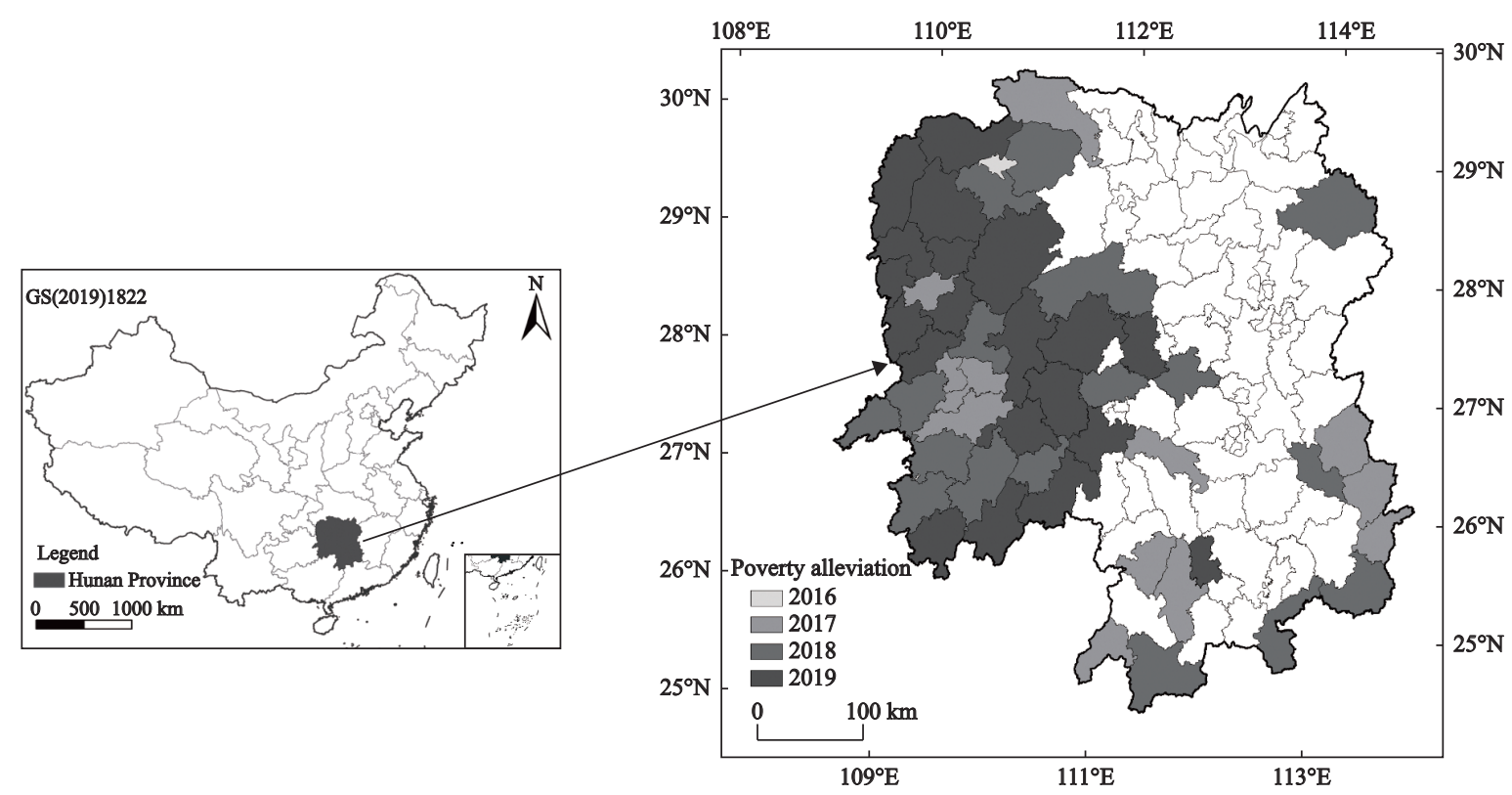

Fig. 1 Location map of Hunan Province, Schematic diagram of poverty alleviation year

cial website of the Poverty Alleviation Office of Hunan Province, as well as the national economic and social statistical bulletin, a government work report on each impoverished county in 2019, and some missing data were filled in by interpolation. DEM (Digital Elevation Model) data with a resolution of $30 \mathrm{~m} \times 30 \mathrm{~m}$ was downloaded from the National Geographic Information Center (https://www.webmap.cn/commres.do?method= dataDownload).

\subsection{Methods}

\subsubsection{Theoretical basis}

The Brundtland report 'Our Common Future' (1987) clearly defined sustainable development, a term which was agreed upon globally in 1992 (Li, 2005). Its core ideas are as follows: healthy economic development should be based on ecological sustainability, social justice, and people's active participation in their own development decisions. As a behavior vector in the complex system of 'Nature-Society-Economy', sustainable development is an important guide for a more reasonable and harmonious development of a country or a region (Niu, 2012). 'Hard support' sustainable development theory deals with the relationship between 'human and nature', and realizes the coordinated evolution of the development of man and nature, society and the environment. 'Soft support' sustainable development theory deals with the relationship between 'human', and its goals are to achieve intra-generational equity and inter-generational justice, pursuit the coordinated development of regional economy, and realize social justice. Poverty eradication has become an important means for the achievement of sustainable development, as it guarantees the sustainable development capacity to all citizens. The targeted poverty alleviation strategy implemented by the Chinese government has lifted 98.99 million rural impoverished people out of poverty, which was the best poverty reduction performance in human history (https://baijiahao.baidu.com/s?id=16926701168 $45574355 \&$ wfr $=$ spider $\&$ for $=\mathrm{pc}$ ). The consolidation of the achievements of poverty alleviation and the sustainability of the achievements of poverty alleviation have become the key tasks for the promotion of sustainable development. The sustainable development of the poverty-stricken areas after poverty reduction covers social, economic, cultural, ecological diversity and other aspects. Through the improvement of the living environment of the relatively disadvantaged groups in povertystricken areas, the stock of geographical capital and its development capabilities are annexed in order to increase poverty alleviation, and as a result the sustainable development ability improves, and, finally, the real state of poverty reduction is achieved. At the same time, based on the reality of the poverty-stricken areas and with the long-term sustainable development in mind, the path of sustainable poverty reduction is explored in order to provide a basis for the formulation of poverty-reduction policies with high efficiency and long-term ef- 


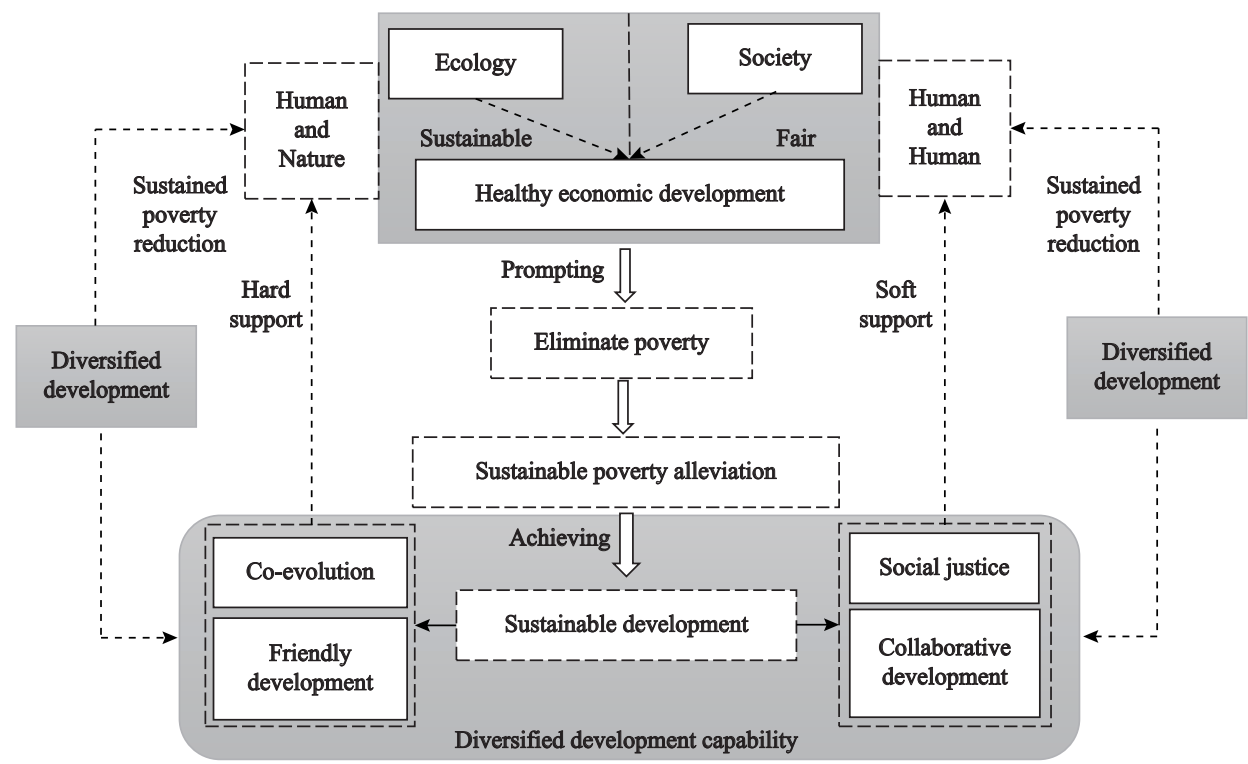

Fig. 2 Theoretical basic framework diagram

fectiveness, and a reference for the decision-making for the realization of sustainable development in rural areas out of poverty is provided (Fig. 2).

\subsubsection{Constructing the evaluation index system}

The overall performance of China's rural areas is a situation of deep poverty, mixed causes, wide distribution, and strong agglomeration (Liu et al., 2016), and the task of poverty alleviation is arduous, complex, and longterm. China's poverty alleviation standard states that if the annual per capita disposable income of the rural poor population is stable above the national poverty standard for the year, then the rural impoverished people will be free from worries about food, clothing, and will have access to compulsory education, basic medical services, and safe housing. This paper comprehensively considers the fairness, multi-dimension, and data availability of the poverty alleviation performance, and selects 17 evaluation indexes covering three dimensions of the economic development, infrastructure, and people's livelihood security of the poverty-stricken counties in contiguously concentrated poverty-stricken areas in order to evaluate the poverty alleviation performance of the 51 counties in the Hunan Province (Table 1). Poverty alleviation performance of the economic development reflects the economic construction capacity and development level of a county. Economic development capacity can measure the degree of a county's poverty alleviation performance, which is mainly represented by indicators such as incidence of poverty, and per capita investment in key projects. The performance of infra- structure poverty alleviation reflects the completeness of the county's infrastructure and is the basic guarantee for the poverty alleviation in the counties. It is mainly measured by indicators such as road network density. and the number of beds in health institutions per 10000 people. The poverty alleviation performance of people's livelihood security reflects the coverage degree of the county social security. The more comprehensive the coverage, the stronger the ability to resist risks, and the better the poverty alleviation performance, which is mainly represented by indicators such as the county's participation in medical insurance rate, and the county's participation in the pension insurance rate.

\subsubsection{Selection of influencing factors}

Since poverty is multidimensional, poverty alleviation needs to be considered from many aspects. Regional poverty is an external manifestation of the imbalance of the three core elements of 'population', 'land', and 'industry' of the development and evolution of the poor regional system (Li et al., 2020). 'Population' is the characteristic of the county's population development, and the main driving force that promotes the county development. It determines the development potential of the county, to a certain extent, and promotes the formation of the spatial differentiation of the poverty alleviation performance. The proportion of the rural labor in the rural population $\left(x_{1}\right)$, the education level per capita $\left(x_{2}\right)$, and the urbanization level $\left(x_{3}\right)$ are selected to reflect the situation of the rural labor force at the county level, the cultural and educational level at the county level, and 
Table 1 Evaluation index system of the poverty alleviation performance in Hunan Province

\begin{tabular}{|c|c|c|c|c|}
\hline Subsystem & Indicator \& Indicator attribute & Weight & Calculation & Unit \\
\hline \multirow{5}{*}{$\begin{array}{l}\text { Economic } \\
\text { development } \\
\text { performance }\end{array}$} & Incidence of poverty $(-)$ & 0.033 & Poverty population/Total population & $\%$ \\
\hline & Per capita investment in key projects $(+)$ & 0.086 & Investment amount of key projects/Total population & yuan (RMB) \\
\hline & $\begin{array}{l}\text { Per capita investment in poverty } \\
\text { alleviation }(+)\end{array}$ & 0.085 & Special funds for poverty alleviation/Poverty population & yuan \\
\hline & Engel coefficient of the rural residents $(-)$ & 0.034 & $\begin{array}{l}\text { Rural food consumption expenditure/Rural total } \\
\text { consumption expenditure }\end{array}$ & $\%$ \\
\hline & $\begin{array}{l}\text { Per capita disposable income of the rural } \\
\text { residents }(+)\end{array}$ & 0.048 & - & yuan \\
\hline \multirow{6}{*}{$\begin{array}{l}\text { Infrastructure } \\
\text { performance }\end{array}$} & Road network density $(+)$ & 0.053 & County mileage/Total area of the county & $\mathrm{km} / \mathrm{km}^{2}$ \\
\hline & $\begin{array}{l}\text { Number of beds in health institutions per } \\
10000 \text { people }(+)\end{array}$ & 0.040 & $\begin{array}{l}\text { Number of beds in health institutions } \times 10000 / \text { Total } \\
\text { population }\end{array}$ & $\begin{array}{l}\text { per ten thousand } \\
\text { people }\end{array}$ \\
\hline & $\begin{array}{l}\text { Pension institutions for every } 10000 \\
\text { people in rural areas }(+)\end{array}$ & 0.055 & $\begin{array}{l}\text { Number of rural nursing homes } \times 10000 / \text { Total rural } \\
\text { population }\end{array}$ & $\begin{array}{l}\text { per ten thousand } \\
\text { people }\end{array}$ \\
\hline & Rural tap water penetration rate $(+)$ & 0.015 & - & $\%$ \\
\hline & $\begin{array}{l}\text { Per capita electricity consumption in rural } \\
\text { areas }(+)\end{array}$ & 0.073 & Rural electricity consumption/Total rural population & $\mathrm{kW} /$ person \\
\hline & $\begin{array}{l}\text { The rate of newly built and renovated } \\
\text { sanitary toilets in rural areas }(+)\end{array}$ & 0.096 & $\begin{array}{l}\text { New and reformed sanitary toilets in rural } \\
\text { areas } \times 10000 / \text { Total number of rural households }\end{array}$ & $\%$ \\
\hline \multirow[t]{6}{*}{$\begin{array}{l}\text { People's livelihood } \\
\text { security performance }\end{array}$} & $\begin{array}{l}\text { The county's participation in the medical } \\
\text { insurance rate }(+)\end{array}$ & 0.009 & $\begin{array}{l}\text { Participation in medical insurance population/Total } \\
\text { population }\end{array}$ & $\%$ \\
\hline & $\begin{array}{l}\text { The county's participation in the pension } \\
\text { insurance rate }(+)\end{array}$ & 0.033 & $\begin{array}{l}\text { Participation in pension insurance population/Total } \\
\text { population }\end{array}$ & $\%$ \\
\hline & $\begin{array}{l}\text { The county's participation in the } \\
\text { subsistence allowance rate }(+)\end{array}$ & 0.069 & $\begin{array}{l}\text { Participation in the subsistence allowances/Total } \\
\text { population }\end{array}$ & $\%$ \\
\hline & $\begin{array}{l}\text { The student-teacher ratio in primary and } \\
\text { secondary schools }(-)\end{array}$ & 0.021 & Total number of students/Total number of teachers & $\%$ \\
\hline & $\begin{array}{l}\text { Transfer rate of the new rural labor force } \\
\text { to employment }(+)\end{array}$ & 0.040 & $\begin{array}{l}\text { Number of newly-increased rural labor force employment } \\
\text { transfers/Total number of the rural labor force }\end{array}$ & $\%$ \\
\hline & $\begin{array}{l}\text { Renovation rate of dilapidated houses in } \\
\text { rural areas }(+)\end{array}$ & 0.210 & $\begin{array}{l}\text { Number of dilapidated houses in rural } \\
\text { reconstruction/Total number of rural households }\end{array}$ & $\%$ \\
\hline
\end{tabular}

Notes: The per capita disposable income of rural residents comes from the Hunan Statistical Yearbook (Statistical Bureau of Hunan Province, 2020). The rural tap water penetration rate comes from the Report on the Work of the Government (2020) (http://www.zjj.gov.cn/c33/20201230/i590057.html). The indicator properties '+' and '-' refer to the relationship between the index value and poverty alleviation performance. '+' is a positive indicator, and '-'is a negative indicator

the income gap between the urban and rural residents, respectively. 'Land' is the foundation of the county development, and the basic reason for the differences in the natural resource endowments and location conditions of each county. The average slope $\left(x_{4}\right)$, the cultivated land area per capita $\left(x_{5}\right)$, and the distance from the county's government to city's government $\left(x_{6}\right)$ are selected to reflect the basic conditions of county production and development, the number of arable land resources, and the intensity of the county's radiation from the central city, respectively. 'Industry' represents the county's economic level, which is an important pillar which supports the development of the county economy.
The improvement of the economic level promotes the improvement of the poverty alleviation performance. The proportion of the primary industry output value of the GDP $\left(x_{7}\right)$, the income ratio of urban and rural residents $\left(x_{8}\right)$, and the total assets of industrial enterprises per capita $\left(x_{9}\right)$ reflect the contribution of the primary industry to the economy of the county, the degree of social progress and comprehensive economic strength of the county, and the assets and development scale of industrial enterprises, respectively (Table 2).

\subsubsection{Measurement model of the poverty alleviation performance}

After the standardization of the above indicators, the en- 
Table 2 Index system and the detection results of the influencing factors of the poverty alleviation effect in Hunan Province

\begin{tabular}{|c|c|c|c|c|c|}
\hline Detection factor & Factors & Unit & Factors attribute & $q$ value & Sort \\
\hline \multirow[t]{3}{*}{ Population } & The proportion of rural labor in the rural population $\left(x_{1}\right)$ & $\%$ & + & 0.867 & 2 \\
\hline & The education level per capita $\left(x_{2}\right)$ & $\%$ & + & 0.860 & 3 \\
\hline & The urbanization level $\left(x_{3}\right)$ & $\%$ & + & 0.427 & 6 \\
\hline \multirow[t]{3}{*}{ Land } & The average slope $\left(x_{4}\right)$ & $\circ$ & - & 0.269 & 9 \\
\hline & The cultivated land area per capita $\left(x_{5}\right)$ & ha/ $/ 10^{4}$ people & + & 0.421 & 7 \\
\hline & The distance from the county's government to the city's government $\left(x_{6}\right)$ & $\mathrm{km}$ & - & 0.840 & 5 \\
\hline \multirow[t]{3}{*}{ Industry } & The proportion of the primary industry output value in $\operatorname{GDP}\left(x_{7}\right)$ & $\%$ & - & 0.873 & 1 \\
\hline & The income ratio of the urban and rural residents $\left(x_{8}\right)$ & $\%$ & - & 0.855 & 4 \\
\hline & The total assets of the industrial enterprises per capita $\left(x_{9}\right)$ & yuan & + & 0.274 & 8 \\
\hline
\end{tabular}

Notes: The education level per capita equals to the population of primary and secondary schools/total number of people in the county. Total assets of the industrial enterprises per capita size are equal to the assets of industrial enterprises above designated size/employees of enterprises. ' + ' is a positive indicator, and '-' is a negative indicator

tropy method was used to calculate the weight of each indicator, and the weight of each indicator was multiplied by the proportion of each indicator after the standardization in order to obtain the performance scores of each poverty alleviation county in different dimensions. The calculation method is as follows:

$S_{i}=100 \times \sum_{j=1}^{m} W_{j} \times P_{i j}$

where, $P_{i j}$ represents the proportion of the $i$ region in the index under the $j$ th index, $W_{j}$ represents the weight of the $j$ th index. $S_{i}$ represents the poverty alleviation performance score of each county. The higher the score, the better the poverty alleviation performance. The sample in the study area, the index, and the total number of indicators are represented by $i, j$, and $m$, respectively.

Geodetector is a statistical method used for the detection of spatial variability, and to reveal a set of statistical methods that affect spatial differentiation forces (Wang and $\mathrm{Xu}, 2017$ ). It can test the spatial differentiation of a single variable, and also detect the logical relationship between two variables, so it is widely used in the process of identification of the dominant factors which affect the spatial differentiation characteristics (Tan and Jiang et al., 2019). In this paper, the influence degree of different factors on the poverty alleviation performance, and the influence size of the double factors superimposed are analyzed using factor detection and factor interaction detection of the geodetector. The calculation method is as follows:
$q=1-\frac{1}{N \sigma^{2}} \sum_{h=1}^{L} N_{h} \sigma_{h}^{2}$

where $q$ is the degree of the explanatory power of the influencing factors on the poverty alleviation performance score, the value range is $[0,1]$, and the closer $q$ is to 1 , the higher the degree of influence on poverty alleviation performance. $N_{h}$ and $N$ are the units of the $h$ county and all counties out of poverty, respectively. $\sigma_{h}^{2}$ and $\sigma^{2}$ are the variances of $Y$ values for the $h$ th county and all counties out of poverty, respectively.

\section{Results and Analysis}

\subsection{Spatial differentiation characteristics of the poverty alleviation performance}

The poverty alleviation performance of the economic development in the Hunan Province shows a 'high-medium-low' cross-distribution pattern in space (Fig. 3a), with a range of 1.178 points and an average score of 0.571 points. The economic development of each county is relatively balanced. The high-performance level of the counties is mainly distributed in the western part of the Hunan Province, such as Longshan County, Fenghuang County, Xinhuang County, etc. These areas have used special poverty alleviation funds and project investments to develop characteristic tourism and industries, which has effectively promoted the optimization and upgrade of the regional industrial structure, the momentum of economic development has been good, and the pace of poverty alleviation has been accelerated. Taking the development of tourism and characteristic 

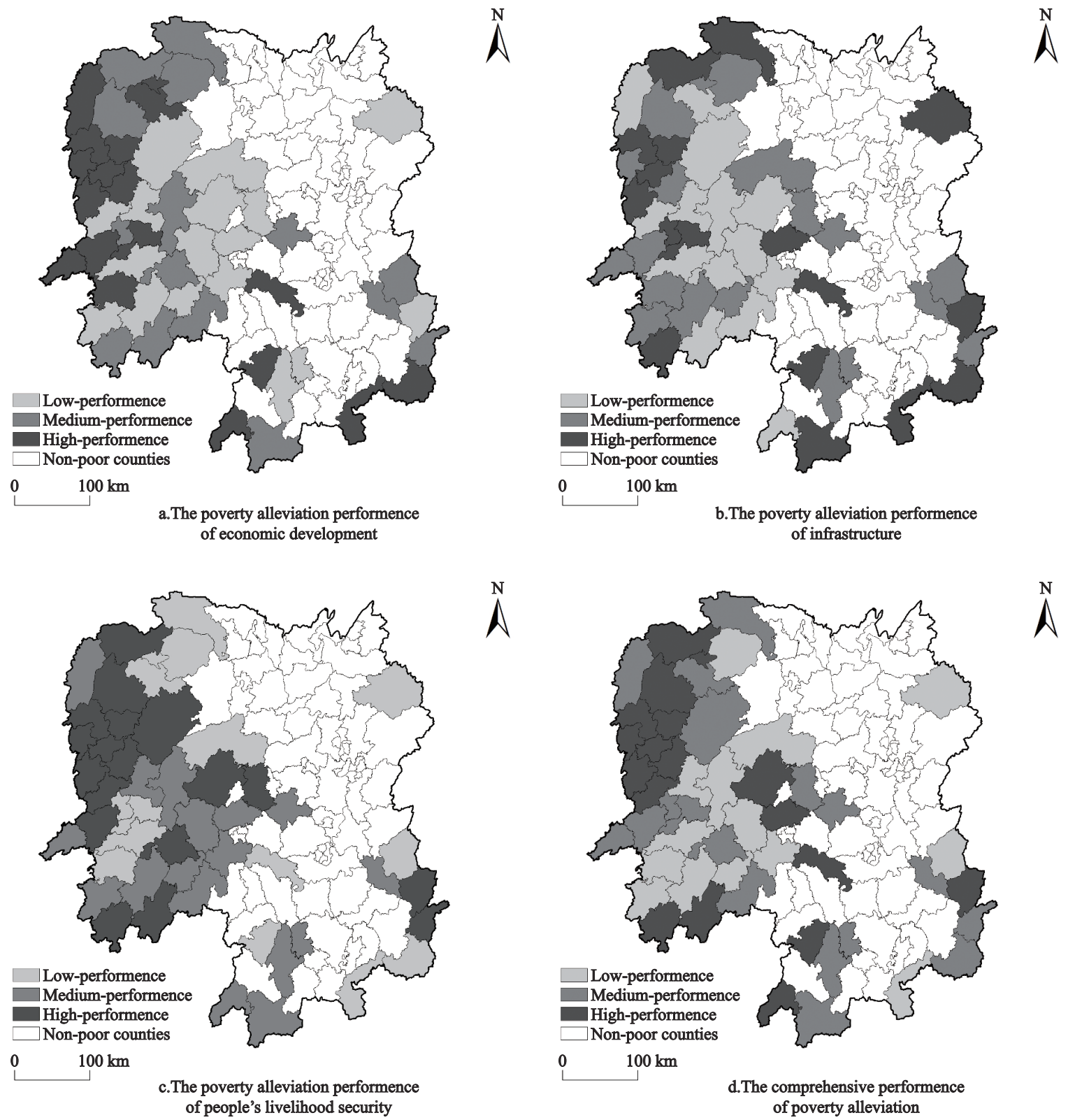

Fig. 3 Spatial distribution of the poverty alleviation performance in the poor counties of Hunan Province

agriculture in Wulingyuan District as an example, the agricultural and sideline products processing industry in Longshan County has promoted the improvement of the economic level to the level of poverty alleviation performance in the economic development. The mediumperformance level of the county is mainly distributed in the northwestern and southwestern marginal areas of the Hunan Province, such as Shimen County, Tongdao County, Jianghua County, etc. The economic development performance of these counties, which have less of an economic impact on the central city and weak regional factor mobility in poverty alleviation, is average. These areas with weak geographical capital, low degree and scale of agricultural industrialization, and relatively insufficient development of the characteristic agricultural industry are struggling to attract investment for key projects, which makes economic growth slow. For example, Longhui County's per capita investment in key projects is only 4622 yuan. The county's large terrain is undulating, which makes it difficult to plant crops which, in turn discourages project investment. In addition, the large number of rural poor population hinders regional economic development to a certain extent, which leads to a low level of performance in the economy.

The poverty alleviation performance of the infrastruc- 
ture in the Hunan Province shows a spatial distribution pattern of 'high on both sides and low in the middle' (Fig. 3b), with a range of 1.316 points and an average score of 0.665 points. The poverty-stricken counties have relatively small gaps in infrastructure construction and balanced levels of improvement. The counties with high-performance are mainly Baojing County, Xinshao County, Rucheng County, and other regions. In recent years, local governments have gradually improved rural infrastructure through the processes of upgrading and reconstructing the power, safe drinking water project, toilet revolution, hardening of roads to households, and other quality improvement measures. As a result, their infrastructure poverty alleviation performance scores are relatively high. For example, Baojing County launched the 'Toilet Revolution', in which 15098 new or renovated toilet households were built. After the Rucheng County has promoted the integration of urban and rural water supply and drainage, the penetration rate of tap water in rural areas has reached $95 \%$, and the performance of infrastructure construction has been remarkable. The counties with medium-performance levels are mainly distributed in the Anhua County, Wugang City, Huitong County, and other areas. These areas have relatively flat terrain and high road network density, but there are a lot of historically problematic areas in the construction and services of the public infrastructure, such as the pension agency, medical care, and electricity, all of which need to be further improved. The lowperformance level of the county is concentrated in Huaihua City and Shaoyang City. These areas have relatively low levels of road construction, rural power, safe drinking water, and medical supporting facilities. Also, these counties are more difficult to upgrade and improve in areas such as transportation, electricity, and drinking water, due to the relatively large terrain undulations, which results in a lower score for the poverty alleviation performance of the regional infrastructure.

The poverty alleviation performance of people's livelihood security in the Hunan Province has significant spatial differentiation characteristics, resulting in a clumped distribution (Fig. 3c). The score range of the performance of the people's livelihood security is 6.642, and the average score is 0.764 . The level of people's livelihood security in the counties out of poverty varies greatly. The counties with high-performance are mainly distributed in Xiangxi City and some areas of Shaoyang
City. The implementation of social security poverty alleviation policies in these counties has produced good results. The participation rate of the endowment insurance, the rate of subsistence insurance, and the employment rate are at a high level. In addition, the remarkable achievements in the renovation of the dilapidated houses make the performance of people's livelihood security in these regions high. For example, the renovation rate of the dilapidated houses in Jishou City has reached 20\%, and housing safety issues have been effectively improved. The middle-performance counties are mainly located in the western part of the Hunan Province, such as Wugang City, Xinhuang County, Suining County, etc. The residents in these counties have a high degree of medical insurance coverage, but their pension insurance participation rate, subsistence allowance rate, and the employment rate of the rural labor force are relatively low, and for those reasons the individual survival and development capabilities of the rural poor are relatively insufficient, which is not conducive to the improvement of the level of people's livelihood security. Counties with low-performance levels are mainly concentrated in the southwest and northwest of Hunan Province, such as Yizhang County, Zhongfang County, Huitong County, etc. The general social security system in these counties is relatively inadequate, and the efforts to renovate dilapidated houses and the pension insurance participation are relatively insufficient, and at the same time, there is a relative imbalance in the distribution of educational resources, in some areas. For example, the proportion of students and teachers in Yizhang County is 20:1, and the relative lack of teachers leads to the low level of poverty alleviation in the regional livelihood security.

The comprehensive performance of the poverty alleviation in poverty alleviation counties in Hunan Province forms a funnel-shaped distribution in space (Fig. 3d), with a range of 8.017 points and an average score of 2.000 points. There is a great spatial difference in the performance of poverty alleviation in different counties. The counties with high-performance are mainly distributed in the western part of the Hunan Province. These counties have relatively complete infrastructure construction and a high level of people's livelihood security combined with the development of regional characteristic tourism and agriculture, such as tea in Guzhang County, ethnic characteristic tourism in 
Fenghuang County, and livestock breeding in Baojing. The performance of these counties in poverty alleviation is at a high level. The counties with medium-performance levels are scattered, mainly distributed in areas such as Jingzhou, Jianghua, and so on. These counties occupy mainly mountainous areas with large landform fluctuation, which makes the construction of transportation and public service facilities difficult, so the implementation of activities has made its poverty alleviation performance relatively low. The counties with low-performance are mainly distributed in Shaoyang City and Huaihua City, such as Huitong County and Suining County, etc. Due to the geographical location, these counties are far away from the central urban agglomeration of the Hunan Province, and are not influenced by the radiation and driving effect of central cities, the regional economic development is limited, and the poverty alleviation performance level is low. In addition, some areas which have a large rural poor population, such as Pingjiang County, Anhua County, Chaling County makes it difficult to maintain the stability of poverty alleviation achievements, which leads to a low level of comprehensive poverty alleviation performance.

\subsection{Influencing factors of the poverty alleviation performance}

\subsubsection{Main influencing factors}

Through the calculation of the geodetector, the results show that the influence of the factors in descending order is as follows: the proportion of primary industry output value in GDP (0.873), the proportion of rural labor in the rural population(0.867), the education level per capita $(0.860)$, the income ratio of urban and rural residents $(0.855)$, the distance from county government to city government (0.840), the urbanization level (0.427), the cultivated land area per capita $(0.421)$, the total assets of industrial enterprises per capita (0.274), the average slope (0.269), respectively. In conclusion, 'population' has the strongest influence on the spatial differentiation of the poverty alleviation performance, followed by 'land' and 'industry'. The proportion of the primary industry output value in GDP, the proportion of rural labor in the rural population, and the income ratio of urban and rural residents are the dominant factors which affect the spatial differentiation of the poverty alleviation counties in the Hunan Province.

Through interaction factor detection, the influence of different factors after superposition is obtained (Table 3 ). The results show that the interaction type of each factor is enhanced by two factors, which signals that there is no independent factor, which in turn indicates that the impact of the interaction of each factor is greater than that of a single factor, that is, the spatial differentiation of the performance of poverty alleviation in the contiguous extreme poverty areas in the Hunan Province is affected by several factors. Among them, the proportion of primary industry output value in GDP and the average slope have the strongest influence on the poverty alleviation performance, with the $q$ value of interaction being 0.978 . Only three pairs of factors interact with $q$ values below 0.9 , and its influence of spatial differentiation is relatively weak. That is, the $x_{3}$ and the $x_{5}$, the $x_{3}$ and the $x_{9}$, and the $x_{5}$ and the $x_{9}$.

\subsubsection{Analysis of the influencing factors}

According to the results of the geodetector, the leading factors, basic factors, and key factors of the spatial differentiation of poverty alleviation performance in contiguously concentrated poverty-stricken areas of the

Table 3 Interaction detector of the geodetector of poverty alleviation effect in Hunan Province

\begin{tabular}{|c|c|c|c|c|c|c|c|c|c|}
\hline Factors & $x_{1}$ & $x_{2}$ & $x_{3}$ & $x_{4}$ & $x_{5}$ & $x_{6}$ & $x_{7}$ & $x_{8}$ & $x_{9}$ \\
\hline$x_{1}$ & 0.867 & & & & & & & & \\
\hline$x_{2}$ & 0.928 & 0.860 & & & & & & & \\
\hline$x_{3}$ & 0.974 & 0.943 & 0.427 & & & & & & \\
\hline$x_{4}$ & 0.978 & 0.930 & 0.967 & 0.269 & & & & & \\
\hline$x_{5}$ & 0.974 & 0.915 & 0.504 & 0.927 & 0.421 & & & & \\
\hline$x_{6}$ & 0.937 & 0.916 & 0.916 & 0.933 & 0.925 & 0.840 & & & \\
\hline$x_{7}$ & 0.963 & 0.922 & 0.930 & 0.958 & 0.956 & 0.921 & 0.873 & & \\
\hline$x_{8}$ & 0.967 & 0.929 & 0.939 & 0.932 & 0.929 & 0.927 & 0.945 & 0.855 & \\
\hline$x_{9}$ & 0.941 & 0.951 & 0.512 & 0.941 & 0.517 & 0.923 & 0.961 & 0.934 & 0.274 \\
\hline
\end{tabular}


Hunan Province are summarized in combination with the positive and negative factors (Table 2, Table 3 ), and the influencing mechanism of the spatial differentiation of the poverty alleviation performance is analyzed in detail (Fig. 4).

'Population' is the characteristic of county population development and the dominant factor affecting the spatial differentiation of the county poverty alleviation performance. The rural labor force is the foundation for the development of rural industries. Sufficient labor resources are conducive to the promotion of the development of industries, boosting the improvement of the rural economic level and the income level of the rural migrant workers, and thus attracting more labor force to find employment, forming a virtuous cycle, and consolidating the performance of the poverty alleviation. In recent years, with the vigorous development of industries in some poverty alleviation counties, the government has encouraged local employment, and the return of rural labor resources has promoted the upgrade and transformation of the regional industries, which has in turn promoted the improvement of the regional poverty alleviation performance, to a certain extent. The education level per capita reflects the education level and educational level of the county, and the education level of residents directly affects their understanding of the poverty alleviation policies and the implementation effect of regional poverty alleviation measures. In addition, education is the main way to block the intergenerational transmission of poverty, and also an important way to im- prove the development ability of the residents. The improvement of the per capita education level promotes multi-directional employment and multi-channel entrepreneurship of the poor population in the region, to a certain extent, which is of great significance to the maintaining of the quality level of the regional poverty alleviation. The urbanization level reflects the social progress in the county. With the rapid advance of urbanization, the efficiency of industrial production has increased, which has stimulated the vitality of the national economic growth. In addition, the improvement of the urbanization level has improved infrastructures such as education, medical care, and public service facilities, at the county level. There has been an improvement in the quality of social services enjoyed by the rural poor and in the performance of poverty alleviation in economic development, infrastructure and livelihood security, at the county level.

'Land' is the basis of the county development, and the basic factor that causes spatial differentiation of the poverty alleviation performance. The average slope affects the cultivation of the county agricultural production and the construction of regional infrastructure. On the one hand, the average slope affects agricultural production activities. For example, when the slope is less than $15^{\circ}$, it is suitable for the growth of crops, and conducive to the development of large-scale agriculture, which in turn promotes the transformation of rural industries and accelerates the pace of the poverty alleviation of the rural poor. On the other hand, the low aver-

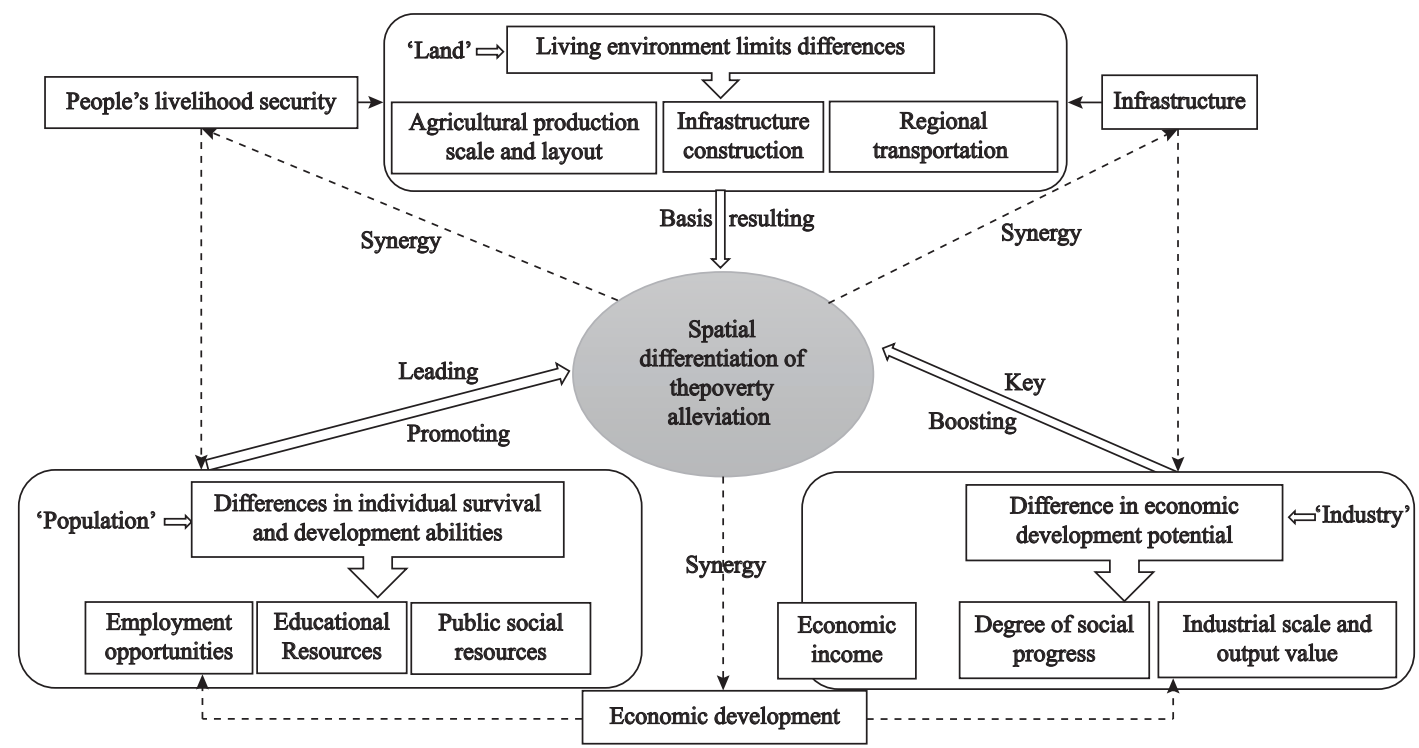

Fig. 4 Influencing factors of the spatial differentiation of the poverty alleviation performance among counties in Hunan Province 
age slope makes the construction of transportation and water conservancy facilities less difficult and cost effective, which is conducive to the promotion of the implementation of the poverty alleviation measures such as infrastructure and public service facilities. Cultivated land resources are the material basis for the development of agricultural production, that is, the basic guarantee for the survival and development of farmers. The area of arable land affects the scale of the agricultural product planting. The large per capita arable land area is conducive to the management and processing of agricultural products, and the formation of the modern agricultural industry chain, such as the vegetable and fruit industry, traditional Chinese medicine industry, flower industry, etc. This in turn helps with the increase of the income of the farmers, and thus promotes the improvement of the level of the poverty alleviation performance. The distance from the county government to the city government reflects the intensity of the county's radiation effect from the economic center of the prefecturelevel city, and affects the industrial development of the poverty-stricken counties. The county closer to the prefecture-level city receives the radiation and driving effect of the economic center of the prefecture-level city, which is beneficial to regional resources. The optimized configuration of the prefecture-level city creates the linking development of the secondary and tertiary industries of the prefecture-level city, improves the level of economic development, and the performance level of the poverty alleviation.

'Industry' is the level of the county economy, and the key factor which affects the development of the county economy. The proportion of primary industry output value in GDP reflects the contribution of the output value of the primary industry to the national economy. Previous studies have shown that the contribution rate of the primary industry correlates positively with the density of the impoverished populations ( $\mathrm{Du}$ et al., 2020). The decline of the contribution rate of the primary industry and the decline of rural poverty have positive effects on the rapid development of the regional economy. At the same time, the low contribution rate of the primary industry indicates that the industrial development of the county is less affected by the factors such as the degree of land use, agricultural conditions, and cultivated land quality, which can promote the stable growth of the county economy and better main- tain the regional poverty alleviation performance level. The income ratio of the urban and rural residents reflects the income gap between the urban and rural residents. The widening of the income gap between urban and rural residents will lead to unbalanced regional economic development, uneven distribution of social resources, and reduced farmers' enthusiasm for production. These problems hinder the stable development of the rural economy and the stable improvement of farmers' living standards, resulting in a relatively low level of poverty alleviation performance. The total assets of the industrial enterprises per capita scale reflect the regional industrial assets and the development scale, which has an important impact on the economic development and population employment. The increase of industrial enterprise assets per capita is conducive to the improvement of the economic strength of the county government, the expansion of the scale is conducive to the employment of rural labor force, the improvement of the county economic development level, and the development ability of farmers, in order to further improve the performance level of the poverty alleviation.

\section{Discussion and Conclusions}

\subsection{Discussion}

As the first stop for the 'precise poverty alleviation', Hunan regards 'industry' as the top priority for poverty alleviation. Comparative analysis of this research and Zhou et al's research (Zhou et al., 2021). Zhou et al. pointed out that the high-quality development of the rural industry is the key to finding the solution for the 'rural disease'. In addition, it is an important driving force which promotes the transformation of Hunan from a traditional agricultural province to a strong modern agricultural province, through the sorting of the achievements and the experience of poverty alleviation in the Hunan Province, and the current situation of the agricultural and rural development. This line of thought is consistent with the conclusion of this study. 'Industry' is the key factor for the improvement of the ability of poverty alleviation counties in contiguous povertystricken areas in the Hunan Province. To consolidate the effective connection between poverty alleviation and rural revitalization in the Hunan Province, it is necessary to realize the optimal allocation of industries in rural areas. At the same time, the results of this study are 
compared with those of Guo et al's research (Guo et al., 2021). The risk of returning to poverty in each village in the concentrated contiguous destitute area is restricted by many factors, and the contribution rate of the risk of returning to poverty of human capital is the highest. This is also similar to the results of this paper, which further proves that 'population' is the dominant factor that affects the stability of poverty alleviation and prevents the return to poverty. In addition, the results of this study are similar to that of Wang et al's research (Wang et al., 2020). The study believes that family-level factors of poor farmers have a stronger impact on the annual net income of the family than environmentallevel factors. However, the impact of environmentallevel factors can not be ignored, as the environmentallevel factors can also have a significant impact. Other factors have a certain impact, which confirms that the geographical difference in this article is the key factor that causes the spatial differentiation of poverty alleviation performance in the Hunan Province. The difference in natural resources and traffic accessibility has no significant impact on the poverty alleviation areas in the Hunan Province. The average slope, especially, has a minimal impact on the spatial differentiation of poverty alleviation performance in Hunan Province. The Hunan Province is a hilly area, the construction of transportation infrastructure has little impact in the short term, but has a long-term significance to the change of the backward state of the poor areas in the Hunan Province. Coordination of the stable operation system of the 'population', 'land' and 'industry' is the only way to eradicate poverty. Consolidating the effective connection between poverty alleviation results and rural revitalization depends on the industrial support and innovative development mechanisms, urban-rural integration, interactive coordination mechanisms, and green ecology. The establishment of long-term mechanisms such as sustainable development mechanisms (Zhou et al., 2021), promotes the sustainable development of the world.

In the times when rural poverty alleviation and rural revitalization overlap, an important issue arises: How to achieve stable poverty alleviation in the concentrated contiguous destitute areas, form a sustainable development model, and promote the effective connection of the rural revitalization strategies? This issue has been discussed by many scholars (Jiao, 2020; Long et al., 2021). Research on the spatial differentiation characteristics and influencing factors of the poverty alleviation performance, at the level of a county, is of great significance to the solution to the shortcomings of the rural development. It can help solve the problem of imbalanced urban-rural development, and activate the rural endogenous power. Promoting the coordinated development of 'population', 'land', and 'industry' in contiguous impoverished areas will help comprehensively promote rural revitalization and accelerate the agricultural and rural modernization. Based on ensuring that the survival ability and development potential of 'population', the ability of the rural poor to sustainably increase income and the 'hematopoiesis' function is improved, the medical assistance system for chronic diseases of the rural poor is straightened, and full coverage of rural medical pension insurance is archived. Based on the existing 'land', the construction of infrastructure and public service facilities, such as elderly care institutions, medical institutions, and teaching institutions is consolidated, in order to ensure that the elderly can provide care for the elderly, the sick can be treated, and the young children can learn, and the improvement of rural roads and the hardening of roads is accelerated. The transformation and upgrading of 'industry' is promoted, the localization of local characteristic industries is carried out, a modern rural industry system with characteristics and competitiveness is established, the formation of a stable and rich industrial chain of regional industries is promoted, and the trend of low quality and homogenization of industries is prevented. By strengthening the sustainable development ability of the concentrated contiguous impoverished areas, the goal of 'industrial revitalization, talent revitalization, cultural revitalization, ecological revitalization, and organizational revitalization' can be achieved. The 51 counties in the Hunan Province, there are two contiguous poverty-stricken areas, Wuling Mountain and Luoxiao Mountain. Through the theoretical and empirical discussion of the performance of poverty alleviation in the counties of this region, it has very important theoretical value and practical guiding significance for the promotion of poverty reduction and sustainable development of the other 12 contiguous and destitute areas in China.

In this paper, the spatial differentiation characteristics and influencing factors of the poverty alleviation performance at the county level in the Hunan Province, in the year 2019, are studied. To some extent, this study 
reflects the current situation of poverty alleviation in the Hunan Province and provides a certain theoretical reference for the promotion of the sustainable development of the Hunan Province. But this research also has shortcomings. Poverty alleviation is a sequential problem. Due to the unavailability of data, it is impossible to conduct a dynamic comparative analysis of multiple time nodes in poverty alleviation counties. The dynamic changes in time and space since the implementation of the poverty alleviation policy in Hunan Province have made it difficult to grasp the concentration of contiguous areas in Hunan Province. At the same time, the scale of this study only stays at the county level, and it fails to study the performance of poverty alleviation from the perspective of farmers who have been lifted out of poverty. Further research on the multi-scale and multi-time node of the performance of poverty alleviation in contiguous poverty-stricken areas needs to be further conducted. As a crucial task of poverty alleviation, poverty in China will undergo three changes in the future: from the governance of absolute poverty in the past to the governance of relative poverty, from the governance of income poverty to the governance of multidimensional poverty, and the governance of rural poverty to the governance of multidimensional poverty. China is still facing various unknown risks and challenges in realizing rural revitalization. In the future, we should start from the micro- and multi-dimensional dimensions, combine the policies of the rural poverty alleviation and rural revitalization, and build a relative poverty indicator system for in-depth research based on field survey data and typical cases. A theoretical basis for poverty alleviation should also be provided.

\subsection{Conclusions}

This paper uses socio-economic statistics, entropy method and geodetector from the county level to study the spatial differentiation characteristics and influencing factors of the poverty alleviation performance in the concentrated contiguous destitute areas, and analyzes different dimensions through the poverty alleviation performance measurement model. Using geodetector to explore the main factors which affect the poverty alleviation in concentrated and contiguous areas, this study aims to provide a theoretical basis for similar areas in order to solve the imbalance of the urban and rural development, continue to consolidate the results of poverty alleviation, and realize the connection of rural poverty alleviation and rural revitalization. The main conclusions are as follows:

(1) The spatial distribution of the poverty alleviated counties in the concentrated contiguous destitute areas in the Hunan Province is integral and regional. The areas with high performance in economic development, infrastructure, people's livelihood security, and comprehensive performance are mainly distributed in the $\mathrm{Xi}$ angxi Autonomous Prefecture, while Huaihua City and Shaoyang City along Xuefeng Mountain are at a relatively low level in all aspects of performance, and their spatial distribution has obvious characteristics of aggregation. The difference between economic development and poverty alleviation performance among counties is small. Strengthening the investment of key projects and poverty alleviation funds can improve the economic development performance of counties in a short term. Infrastructure can also be achieved through the renovation of the rural sanitary toilets, and the construction of medical and pension facilities, with the goal of making the province's infrastructure construction relatively balanced. Increasing the employment rate of the rural labor force and improving the rural housing environment can improve the level of people's livelihood security, but ethnic customs, and cultural and educational concepts restrict the flow of labor and the choice of employment space, with different regions having different understandings of national policies. The protection policies for the benefit of the people issued by local governments will also vary from person to person and from place to place, resulting in large differences in the coverage of people's livelihood security.

(2) The geodetector model shows that the spatial differentiation of poverty alleviation performance in the concentrated contiguous destitute areas of the Hunan Province is the result of multiple factors, which are affected by industrial development, rural labor resources, educational resources, income structure, and transportation accessibility. The influence of each factor is greater than that of a single factor. The proportion of the primary industry of GDP has the greatest impact on poverty alleviation performance, but it also has a severely negative impact. Increasing the contribution rate of the secondary and tertiary industries to the GDP can promote the improvement of poverty alleviation performance. The number of rural labor forces and the 
education level of primary and middle school students have a significant positive impact on the poverty alleviation. The popularization of education and culture in rural areas and the improvement of rural labor's cultural literacy can effectively promote poverty alleviation. The average slope and the area of cultivated land have no significant impact on the poverty alleviation performance of the concentrated contiguous destitute areas. The interaction of labor and other factors has the greatest impact on the spatial differentiation of the poverty alleviation performance. Labor is the fundamental driving force for economic development, and the supply of labor plays an important role in the poverty alleviation in rural areas.

\section{References}

Akinlolu O J, Maina A D, 2020. Transportation and poverty reduction in yobe state. Direct Research Journal of Social Science and Educational Studies, 7(6): 153-167. doi: 10.26765/ drjsses5091231321

Alkire S, Santos M E, 2010. Acute Multidimensional Poverty: A New Index for Developing Countries. Working Paper No. 38. DOI: $10.2139 /$ ssrn. 1815243

Bahrami M B, Hashimee A H, 2019. Poverty and ways for its reduction: Case Study of Afghanistan. International Journal for Innovative Research in Multidisciplinary, 5(11): 75-82.

Callixte K, Mahina J N, Tushabe E, 2020. The contribution of absolute income towards poverty reduction in Sub-Saharan Africa: the case of Rwanda. East African Journal of Business and Economics, 2(1): 110-117. doi: 10.37284/eajbe.2.1.255

Dou Tongyu, Tang Qingyuan, Bin Jinyou et al., 2018. Spatial patterns and formation mechanism of poverty in village-scale: a case of Fenghuang county, Hunan Province. Areal Research and Development, 37(6): 155-159, 172. (in Chinese)

Du Guoming, Feng Yue, Yu Jiaxing, 2020. Poverty pattern and influencing factors in typical deep poverty-stricken counties: a case study of Hailun city in Heilongjiang province. Progress in Geography, 39(1): 69-77. (in Chinese)

Dunford M, Gao B Y, Li W B, 2020. Who, where and why? Characterizing China's rural population and residual rural poverty. Area Development and Policy, 5(1): 89-118. doi: 10.1080/23792949.2019.1571425

Geremewe Y T, 2019. The role of microfinance institution for poverty reduction in Ethiopia. Journal of Economics and Sustainable Development, 10(5): 36-44. doi: 10.7176/JESD/10-504

Guo Qian, Liao Heping, Wang Ziyi et al., 2021. Measurement of rural poverty alleviation sustainability and return-to-poverty risk identification in Qinling-Bashan Mountains: a case study of Chengkou county, Chongqing municipality. Progress in Geography, 40(2): 232-244. (in Chinese)

Guo Yuanzhi, Zhou Yang, Cao Zhi, 2018. Geographical patterns and anti-poverty targeting post-2020 in China. Journal of Geographical Sciences, 28(12): 1810-1824.

Habtewold T M, 2021. Impact of climate-smart agricultural technology on multidimensional poverty in rural Ethiopia. Journal of Integrative Agriculture, 20(4): 1021-1041. doi: 10.1016/ S2095-3119(21)63637-7

Hu Yuan, Zeng Weizhong, 2019. Evaluation of poverty alleviation process in counties at high poverty levels based on PSR model: a case of Sichuan province. Resources and Environment in the Yangtze Basin, 28(12): 2867-2878. (in Chinese)

Hunan Survey Yearbook. 2020. Statistical Bureau of China in Hunan Survey Team. Beijing: China Statistics Press. (in Chinese)

Hunan Rural Statistical Yearbook, 2020. Statistical Bureau of Hunan Province. People 's Republic of China. Beijing: China Statistics Press. (in Chinese)

Hunan Statistical Yearbook, 2020. Statistical Bureau of Hunan Province. People's Republic of China. Beijing: China Statistics Press. (in Chinese)

Jiao Wenxian, 2020. Analyzing multidimensional measures of poverty and their influences in China 's Qinba Mountains. Chinese Journal of Population, Resources and Environment, 18(3): 214-221. doi: 10.1016/j.cjpre.2021.04.002

Jin Gui, Deng Xiangzheng, Dong Yin et al., 2020. China's multidimensional poverty measurement and its spatiotemporal interaction characteristics in the perspective of development geography. Acta Geographica Sinica, 75(8): 1633-1646. (in Chinese)

Langlois A, Kitchen P, 2001. Identifying and measuring dimensions of urban deprivation in montreal: an analysis of the 1996 census data. Urban Studies, 38(1): 119-139. doi: 10.1080/ 00420980124734

Leventi C, Sutherland H, Tasseva I V, 2019. Improving poverty reduction in Europe: what works best where? Journal of European Social Policy, 29(1): 29-43. doi: 10.1177/ 0958928718792130

Li Longxi, 2005. The annotation and the resolution of the sustained development theories. Administration and Law, (1): 3-7. (in Chinese)

Li Xunhuan, Zhou Yang, Chen Yufu, 2020. Theory and measurement of regional multidimensional poverty. Acta Geographica Sinica, 75(4): 753-768. (in Chinese)

Li Yilong, Liao Heping, Li Tao et al., 2018. Rurality evaluation and precision poverty alleviation model in urban and suburban areas: a case study of 138 villages in Yubei district of Chongqing. Journal of Southwest University (Natural Science Edition), 40(8): 56-66. (in Chinese)

Liu Xiaopeng, Li Yonghong, Wang Yajuan et al., 2017. Geographical identification of spatial poverty at county scale. Acta Geographica Sinica, 72(3): 545-557. (in Chinese)

Liu Xinmei, Han Linzhi, Zheng Jianghua et al., 2019. Temporalspatial characteristics and the driving mechanism of multidimensional comprehensive poverty degree in poverty-stricken counties: a case study of poor counties in deep poverty-stricken areas of southern Xinjiang. Economic Geography, 39(7): 165-174. (in Chinese)

Liu Yansui, Zhou Yang, Liu Jilai, 2016. Regional differentiation 
characteristics of rural poverty and targeted poverty alleviation strategy in China. Bulletin of Chinese Academy of Sciences, 31(3): 269-278. (in Chinese)

Long Hualou, Chen Kunqiu, 2021. Realizing Effective Connection of Consolidating and Expanding the Achievements of Poverty Alleviation and Rural Vitalization: Research Framework and Prospects. Economic Geography, 41(8): 1-9. (in Chinese)

Magombeyi M T, Odhiambo N M, 2018. Dynamic impact of FDI inflows on poverty reduction: empirical evidence from South Africa. Sustainable Cities and Society, 39: 519-526. doi: 10.1016/j.scs.2018.03.020

Nhung N T, 2020. The implementation of poverty reduction policies in Thai Nguyen province. International Journal of $\mathrm{Ad}$ vance Research and Innovative Ideas in Education, 6(3): 505-511.

Niu Wenyuan, 2012. The theoretical connotation of sustainable development: the 20th anniversary of UN conference on environment and development in Rio de Janeiro, Brazil. China population Resources and Environment, 22(5): 9-14. (in Chinese)

Padda I U H, Hameed A, 2018. Estimating multidimensional poverty levels in rural Pakistan: a contribution to sustainable development policies. Journal of Cleaner Production, 197: 435-442. doi: 10.1016/j.jclepro.2018.05.224

Ponce P, Aguirre-Padilla N, Oliveira C et al., 2020. The spatial externalities of tourism activities in poverty reduction. Sustainability, 12(15): 6138. doi: 10.3390/su12156138

Qi Wenping, Wang Yanhui, Wan Yuan et al., 2020. Multi-objective development evaluation of poverty-stricken households based on G-TOPSIS model: a case study from Fugong county, Yunnan province. Progress in Geography, 39(6): 1024-1036. (in Chinese). doi: 10.18306/dlkxjz.2020.06.012

Rajesha M G, Alok G, 2018. Microfinance and poverty reduction in India. Globus - An International Journal of Management and IT, 9(2): 1-6.

Rogers S, Li J, Lo K et al., 2020. China's rapidly evolving practice of poverty resettlement: moving millions to eliminate poverty. Development Policy Review, 38(5): 541-554. doi: 10.1111/dpr. 12435

Shabbir M S, Abbas M, Aman Q et al., 2019. Poverty Reduction Strategies. Exploring the link between Poverty and Corruption from less developed countries. Revista Dilemas Contemporáneos:Educación, Política y Valores, 6(2): 1-20.

Sikandar F, Erokhin V, Wang H S et al., 2021. The impact of foreign capital inflows on agriculture development and poverty reduction: panel data analysis for developing countries. Sustainability, 13(6): 3242. doi: 10.3390/su13063242

Tan Xuelan, An Yue, Wang Zhenkai et al., 2019. Research on influencing factors and regulating paths of rural poverty in Hunan Province. Geographical Research, 38(11): 2804-2815. doi: 10.11821/dlyj020190274

Tan Xuelan, Jiang Lingxiao, Mi Shengyuan et al., 2019. Performance evaluation and spatial differentiation of rural anti-poverty at county scale in Hunan Province. Scientia Geographica Sinica, 39(6): 938-946. (in Chinese)

Tesema D, 2020. Critical linkages: poverty, livelihoods, institu- tions, and community development in poverty reduction. $\mathrm{Pub}$ lic Policy and Administration Research, 10(6): 6-11. doi: 10.7176/PPAR/10-6-02

Umidjanovich T B, 2020. Directions of poverty reduction through the development of cooperative entrepreneurship in rural areas. European Journal of Molecular \& Clinical Medicine, 7(6): 2416-2425.

Urbano B, Jurado A, Rosado-Cebrián B, 2021. What will retirement pensions be like? Analysis of Spanish future pensioner households in terms of poverty. Sustainability, 13(4): 1760. doi: $10.3390 /$ su13041760

Wang Binyan, Tian Junfeng, Shi Xiang et al., 2020. Rural Poverty of Wangqing County Beased on HLM and GWR. Scientia Geographica Sinica, 40(3): 409-418. (in Chinese)

Wang Degen, Sha Mengyu, Zhao Meifeng, 2020. The spatial pattern and differentiation mechanism of poverty alleviation in national poverty counties. Scientia Geographica Sinica, 40(7): 1072-1081. (in Chinese)

Wang Jinfeng, Xu Chengdong, 2017. Geodetector: principle and prospective. Acta Geographica Sinica, 72(1): 116-134. (in Chinese)

Wang Yanhui, Chen Yefeng, Chi Yao et al., 2018. Village-level multidimensional poverty measurement in China: where and how. Journal of Geographical Sciences, 28(10): 1444-1466. doi: 10.1007/s11442-018-1555-0

Wu Peng, Li Tongsheng, Li Weimin, 2018. Spatial differentiation and influencing factors analysis of rural poverty at county scale: a case study of Shanyang county in Shaanxi province, China. Geographical Research, 37(3): 593-606. (in Chinese)

Zandi R, Zanganeh M, Akbari E, 2019. Zoning and spatial analysis of poverty in urban areas (Case Study: Sabzevar City-Iran). Journal of Urban Management, 8(3): 342-354. doi: 10.1016/j.jum.2019.09.002

Zhao Chunyu, Wen Ruixia, Yang Na, 2020. The influence mechanism of poverty spatial differentiation in Western Anhui province. Journal of Natural Resources, 35(12): 2916-2928. doi: 10.31497/zrzyxb.20201208

Zheng Dianyuan, Wen Qi, Huang Xiaojun, 2021. The regional differentiation mechanism of rural multidimensional poverty in arid sandy area. Scientia Geographica Sinica, 41(1): 149-156. (in Chinese)

Zhou Guohua, Yu Xuexia, He Yanhua et al., 2021. Thoughts on The Effective Connection Between Consolidating the Achievements of Poverty Alleviation and Rural Revitalization in Hunan Province. Economic Geography, 41(8): 10-18. (in Chinese)

Zhou Yang, Li Xunhuan, 2019. Geographical pattern and mechanism of poverty differentiation in plain areas: a case study of Lixin county, Anhui province. Scientia Geographica Sinica, 39(10): 1592-1601. (in Chinese)

Zhu Shu, Feng Yanfen, Wang Fang et al., 2018. Evaluation and classification of poverty alleviation potential of relatively poor villages in mountainous areas of northern Guangdong province: a case study of Lianzhou city. Journal of Natural Resources, 33(8): 1304-1316. (in Chinese). doi: 10.31497/ zrzyxb.20180114 